\title{
Managerial Perspectives on Integration of Complementary and Alternative Medicine Services into the Ghanaian Public Healthcare System: An Exploratory Study
}

\section{Maame Yaa Pomaa Nhyira Essel}

Ghana Health Service, Greater Accra Regional Hospital, Public Health and Research Department

\section{Samuel Amon}

University of Ghana School of Public Health

\section{Samuel Agyei Agyemang}

University of Ghana School of Public Health

\section{Moses Aikins ( $\square$ mksaikins@ug.edu.gh )}

University of Ghana School of Public Health https://orcid.org/0000-0002-2370-4006

\section{Research}

Keywords: Complementary and alternative medicine, Ghana, integration, orthodox medicine, Traditional medicine

Posted Date: April 6th, 2021

DOI: https://doi.org/10.21203/rs.3.rs-365839/v1

License: @ (i) This work is licensed under a Creative Commons Attribution 4.0 International License. Read Full License 


\section{Abstract}

Background This study explores healthcare managers' perspective of integration of CAM service into Ledzorkuku Krowor Municipal (LEKMA) Hospital in Ghana.

Methods A questionnaire on CAM services integration was constructed and distributed to all 9 healthcare managers at the Ledzorkuku Krowor Municipal (LEKMA) Hospital.

Results The level of integration of CAM services into the health care system was good. The overall selfreported depth of integration was found to be good (2.23), the self-reported extent of was $100 \%$ and perceived scope of integration was classified as excellent (90.1\%). The drivers of integration process were made up of $7(19.1 \%)$ of the elements of integration functions (47) assessed.

Conclusion The drivers of integration were mainly the elements of integration functions of patient satisfaction, right of patients to use other services, interpersonal systems, monitoring and supervision systems, nature of working relationship among staff, reporting, and financial management.

\section{Introduction}

Complementary and alternative medicine (CAM) are categorized as diverse medical therapies and health care practices that are not presently considered as part of orthodox medicine [1]. The World Health Organization also defines "complementary medicine" or "alternative medicine" as a vast set of health care therapies that usually do not form a part of that country's traditional or conventional medicine and as such are not fully integrated into the dominant health-care system [2]. CAM services are very diverse and include a wide range of therapies namely alternative medical systems, mind-body interventions, biologically-based treatments, manipulative and body-based methods and energy therapies $[3,4,5]$.

Evidence from World Health Organisation suggests that traditional medicine is the most widely used and of rapidly growing health system and economic importance. Usage worldwide ranges from about $38 \%$ in Belgium up to $80 \%$ in Africa [6]. Moreover, the World Health Organisation noted that in many parts of the world, expenditure on traditional medicine/ Complementary and Alternative Medicine (TM/CAM) is not only significant, but growing rapidly. The estimates range from US\$ 80 million in Australia to US\$2.7 billion in the USA. The broad use of traditional medicine in developing countries is often attributed to its accessibility and affordability [6].

In most countries around the world, CAM services is often integrated as a mechanism for addressing therapeutic gaps in the management of chronic and acute illnesses, maintaining health and improving the quality of health care $[7,8,9,10,11,12,13,14,15,16,17,18,19]$, to deliver a client-centred and holistic primary health care service, and promote mutual respect among practitioners of CAM and conventional medicine [20]. In sum, proponents have noted that integration creates better health care experience, is culturally acceptable, improves accessibility and availability of services, decreases the cost of health care delivery and promotes better health outcomes. 
As part of integrating CAM services into mainstream health services in Ghana, the Ministry of Health amended the National Health Policy following the establishment of a policy of herbal medicine practice in 2005 [21]. Then in 2010, the Traditional Medicine Practice Council (TMPC) was set up following the release of the second edition of the Ghana Herbal Pharmacopoeia (GHP) in 2007 [22]. Thus in 2012, herbal medicine practice was formally integrated into the main health service delivery system in Ghana, with pilot projects in about 18 public facilities nationwide [22]. Thereafter, in some selected regional hospitals in Ghana, herbal medicine has thus become accessible to the general public on a pilot basis. Currently, the Ghana Health Service in collaboration with the Ministry of Health is piloting herbal medicine services in 15 government hospitals across the country. Furthermore, about 30 Kwame Nkrumah University of Science and Technology (KNUST) trained herbal medicine graduates in the category of Physician Assistants (herbal) are involved in this pilot project. These Physician Assistants are currently prescribing about 30 registered herbal products from the essential herbal medicine list [23]. This training is ongoing.

This study explores the depth and extent, perceived scope and drivers of integration of CAM services into one of the pilot hospitals in Ghana. Findings of this study will provide first-hand information on depth and extent, scope and drivers of CAM services integration in Ghana. Furthermore, it will inform other countries, mainly in sub-Saharan Africa insight into the feasibility of CAM services integration to improve comprehensive health service delivery.

\section{Materials And Methods}

\section{Study setting and design}

The study was a quantitative managerial facility-based cross-sectional study. Ehical approval for the study was obtained from the Ghana Health Service Ethics Review Committee (i.e., certificate number GHS-ERC: 19/03/17). The study was conducted at the Ledzorkuku Krowor Municipal hospital, a government hospital built by the Chinese government in 2010. The hospital is one of the centres selected by the Ghana Health Service for the integration of CAM service. The hospital is a 100-bed capacity hospital that has all the units of a general hospital including special services, laboratory and radiological facilities. They have as well in addition a Malaria Research Centre and a Herbal Medicine Unit. It has a clinical staff of about 22 doctors of which 9 are specialists and over 200 nurses. The Herbal Medicine Unit provides clinical consultation and general health counseling. It also has a Massage Unit that provides therapeutic child massage, adult general body massage, weight management, stress management and pain management services. Acupuncture and moxibustion services are also available within the Centre and is provided by both herbal medicine practitioners and traditional Chinese Medicine expert.

\section{Participants}

The study population comprised of all the department and unit heads of Ledzorkuku Krowor Municipal hospital (i.e. Head of CAM unit, Director of Finance, Head of Pharmacy, Deputy Director of Nursing Services, Head of Paediatric unit, Procurement head, Head of internal medicine, Head of surgery 
department and the Medical superintendent). These department and unit heads are either directly or indirectly involved in the administration, governance and decision making of the hospital.

\section{Data collection}

Prior to data collection consent was obtained from all these health managers. Data were collected in May 2017. Data were collected using a closed-ended structured questionnaire. Table 1 shows the different CAM integration principles and their respective elements of integration function on which data were collected. Browne et al 5-point depth of integration scores was used to assess the CAM integration principles [24]. These score ranges from 0 (non-awareness), 1 (awareness), 2 (communication), 3 (cooperation) to 4 (collaboration). Each integration principle was made up of a series of integration functions which were assessed. Additionally, the following demographic and background data were collected from participants sex, age and duration spent in position at work.

\section{Data analysis}

\section{Services integration measure}

The study determined four aspects of services integration measure of CAM services at the Ledzorkuku Krowor Municipal hospital. These included: (1) self-reported depth of integration (2) self-reported extent of CAM integration, (3) perceive scope of integration, and (4) drivers of integration.

\section{Self-reported depth of integration}

This was determined by identifying the health services integration principles related to CAM services that has been integrated into Ledzorkuku Krowor Municipal hospital health services. Each depth of integration component was measured along a continuum ranging from 0 to 4 . Table 2 shows the ordinal scale adapted from Browne et al that was used [24]. The average scores assigned to each integration principle by respondents represented the depth of integration.

\section{Self-reported extent of integration}

This was determined by identifying the health services integration principles that relates to CAM services that has been integrated into Ledzorkuku Krowor Municipal hospital health services scoring between 1-4 representing indicator classifications of "Mild integration" to "Perfect integration" as shown in Table 2.

\section{Perceived scope of integration}

This measures the number of services that have an awareness or linkage with other services. The value of the scope of integration is the percentage of integration principles assigned a score higher than zero (0) by respondents using the ordinal scale in Table 2.

\section{Drivers of integration}


Drivers of the process of integration are the integration principles that facilitate or enable the process of integration to be successful. Health system principles found to have average scores above 2.5 were considered to be drivers of the process of integration in Ledzorkuku Krowor Municipal hospital. These are the indicator classifications ranging between good and perfect integration as shown in Table 3.

\section{Total Integration Score}

The total integration score measures the average depth of integration among all the integration elements listed. Based on Table 3, the scores were re-categorized ranging from very little integration (0.0 - 0.49) to perfect integration $(3.5-4.00)$.

\section{Results}

\section{Background characteristics of participants}

Table 4 shows that about (56\%) of participants were male, (22.2\%) of whom were older than 45 and $44.4 \%$ aged less than 45. Two study participants did not divulge their ages. About (55.6\%) of the participants had worked for more than 5 years.

\section{Self-reported depth of integration}

The results for the self-reported depth of integration is presented in Fig. 1. The average scores for the selfreported depth of integration ranged from 2.0 (i.e. Information systems and standardized health care) to 2.7 (i.e. financial management). All integration element averagely scored 2 and above. The overall selfreported depth of integration was 2.23 .

\section{Self-reported extent of integration}

Self-reported extent of integration was 47 (100\%). All the indicator classifications ranges from "Mild integration" to "Perfect integration".

\section{Perceived scope of integration}

Fig. 2 shows that the perceived scope of integration ranged from $(62.9 \%-93.6 \%)$. The overall perceived scope of integration of CAM in the health services at Ledzorkuku Krowor Municipal was about $90.1 \%$. The comprehensive services components had the highest integration percentage score of (93.6\%). Health workforce integration obtained the least score of about (63\%).

Most of the elements of integration functions forming the integration principles (58\%) were scored to have good integration into the health system. About $17 \%$ were also scored to have integrated moderately, $(6 \%)$ were scored to have mildly integrated and $(4 \%)$ scored have integrated excellently into the existing health system.

\section{Drivers of CAM services integration}


Table 5 shows that the elements of integration function found to drive the process of integration were: 1) patient satisfaction; 2) right of patients to use other services; 3) interpersonal systems; 4) monitoring and supervision systems; 5) nature of working relationship among staff; 6) reporting; and 7) financial management. Auditing, staff remuneration and funding sources were the indicators of financial management element that drove the service integration. As shown in Table 5, these elements of integration functions had scores that ranged from 2.56 (for both standardized health systems and interpersonal teams) to a maximum of 3.11 (for funding sources and rights of patients to use other services). This forms $14.9 \%$ of the 47 elements of integration functions assessed.

\section{Discussion}

The study explored the depth and extent, scope and drives of integration of CAM services into the healthcare system at Ledzorkuku Krowor Municipal hospital. Our results suggest that the overall selfreported depth of integration was good with all integration element averagely scoring 2 and above. This implies that CAM services actively share information and communication on a formal basis, modify their own service planning to avoid service duplication or to improve links among services and, jointly plan their services offered and modify their own services as a result of mutual consultations and advice. Secondly, overall perceived scope of integration of CAM services in the health services at Ledzorkuku Krowor Municipal was about (94\%). The comprehensive services components had the highest integration percentage score of $93 \%$, most of the elements of integration functions forming the integration principles (58\%) were scored to have good integration into the health system. Finally, the elements of integration function found to drive the process of integration were: 1) patient satisfaction; 2) right of patients to use other services; 3) interpersonal systems; 4) monitoring and supervision systems; 5) nature of working relationship among staff; 6) reporting and; 7) Financial management.

World Health Organisation (2008) has stated that, integration is "The organization and management of health services so that people get the care they need, when they need it, in ways that are user friendly, achieve the desired results and provide value for money". Accordingly, the integration process in Ghana was initiated with the aim of improving access to comprehensive health care to most people, and maximizing gains from both orthodox and alternative medicine. Thus, results of this study show that CAM service is well integrated into the health system at Ledzorkuku Krowor Municipal hospital. It is also worth noting, the drivers of integration identified will require regular monitoring to allow for the achievement of the set objectives of the CAM Centre [25]. Also, paying attention to staff issues [26] will result in high patronage and high level of patient satisfaction at the CAM Centre [27].

The literature on measurement of integrated healthcare delivery is relatively scanty and also reveals a wide range of concepts and methods. This has made it difficult to compare this study findings to others. There seems to exist some amount of difficulty in measuring integrated services in health systems and thus no consensus on how to measure the concept, which makes monitoring of the process quite difficult [28]. However, since assessment of integration of services is a relative new area in the health system, there are no established measures that suit any given purpose. The method selected in any assessment on measure 
of integration would be dependent on the objective of the study. This study adapted the model of measuring services integration proposed by Browne et. al.[24] which response appropriately to the objective of this study - self-reported depth and extent, scope and drivers of integration. According to this method, every organization keeps its own structure but agrees to participate within an "umbrella" system and to adapt its operations and resources to the agreed requirements and processes. Other studies on assessing the extent of integration were limited in scope, dealing mainly with depth and extent of integration $[29,30,31,32]$. This suggests that measurement of integration of services is generally seen to be challenging and evolving. The measures of integration determined in this study helps to identify services that cooperate and collaborate with each other.

Given the measures of integration - depth and extent, scope and drivers - determined in this study, it will be useful that similar exercises are carried out in the other pilot CAM projects in public facilities nationwide, so that enough evidence will be obtained on the integration of CAM services. These results will be of immense benefit to Ghana Health Service in re-structuring where appropriate and for the scale-up of CAM services in the country to improve effective and deliver comprehensive health service as envisaged by World Health Organisation [33].

\section{Conclusion}

CAM services seem to have been well integrated into Ledzorkuku Krowor Municipal health system with good depth and extent and scope of integration. The drivers of integration were mainly the elements of integration functions of patient satisfaction, right of patients to use other services, interpersonal systems, monitoring and supervision systems, nature of working relationship among staff, reporting, and financial management. These measures of integration could be used to inform re-structuring and the scale-up of CAM services in Ghana.

\section{Declarations}

\section{Acknowledgments}

We express our profound gratitude to all the staff Ledzorkuku Krowor Municipal (LEKMA) Hospital for their participation in the study and support.

\section{Funding}

This research was not funded by any agency

\section{Authors' contributions}

MYPNE: Conceptualization, Data curation, Formal analysis, Investigation, Methodology, Visualization, Writing - original draft. SA: Data curation, Software, Formal analysis, Investigation, Methodology, Visualization, Writing - original draft. SAA: Data curation, Software, Formal analysis, Investigation, 
Methodology, Visualization, Writing - original draft. MA: Conceptualization, Data curation, Formal analysis, Investigation, Methodology, Visualization, Writing - original draft, Writing - review \& editing.

\section{Availability of data and materials}

The datasets used and/or analysed during the current study are available from the corresponding author on reasonable request

\section{Declarations}

\section{Competing interest}

The authors hereby declare no conflict of interest in this study.

\section{Consent for publication}

Not applicable.

\section{Ethics approval and consent to participate}

Ethical approval was sought from the Ghana Health Service Ethics Review Committee (i.e., certificate number GHS-ERC: 19/03/17). Also, permission was sought from the Greater Accra Regional Directorate of the Ghana Health Service and the Ledzorkuku Krowor Municipal (LEKMA) Directorate of Health Services. The purpose of the study was also explained to respondents and their written consent was given.

\section{Author Information}

Affiliations

Greater Accra Regional Hospital, Public Health and Research Department

Maame Yaa Pomaa Nhyira Essel

Department of Health Policy Planning and Management, School of Public Health, University of Ghana

Samuel Amon, Samuel Agyei Agyemang \& Moses Aikins

\section{References}

1. Kuunibe N, Domanban P. Demand for Complementary and Alternative Medicine in Ghana. International Journal of Humanities and Social Sciences. 2012;2.

2. World Health Organisation. WHO traditional medicine strategy: 2014-2023. . WHO, Geneva, Switzerland. 2013. http://www.searo.who.int/entity/health_situation_trends/who_trm_strategy_20142023.pdf?ua=1. 
3. Abdullahi AA. Trends and challenges of traditional medicine in Africa. African journal of traditional, complementary, and alternative medicines : AJTCAM. 2011;8(5 Suppl):115-23. doi:10.4314/ajtcam.v8i5S.5

4. Frass $M$, StrassI RP, Friehs $H$, Mullner M, Kundi M, Kaye AD. Use and acceptance of complementary and alternative medicine among the general population and medical personnel: a systematic review. Ochsner J. 2012;12(1):45-56.

5. Tabish SA. Complementary and Alternative Healthcare: Is it Evidence-based? International journal of health sciences. 2008;2(1):V-IX.

6. World Health Organisation. WHO Traditional Medicine Strategy: 2002-2005. WHO, Geneva, Switzerland. 2002.

http://www.wpro.who.int/health_technology/book_who_traditional_medicine_strategy_2002_2005.pdf.

7. Barnes PM, Bloom B, Nahin RL. Complementary and alternative medicine use among adults and children: United States, 2007. Natl Health Stat Report. 2008(12):1-23.

8. Braun LA, Stanguts C, Casanelia L, Spitzer O, Paul E, Vardaxis NJ, et al. Massage therapy for cardiac surgery patients-a randomized trial. J Thorac Cardiovasc Surg. 2012;144(6):1453-9, 59.e1.

9. Burke A, Ginzburg K, Collie K, Trachtenberg D, Muhammad M. Exploring the role of complementary and alternative medicine in public health practice and training. J Altern Complement Med. 2005;11(5):9316.

10. Esmail N. Complementary and alternative medicine in Canada: Trends in use and public attitudes, 1997-2006. Public Policy Sources. 2007;87:1-53.

11. Grace S, Higgs J. Integrative medicine: enhancing quality in primary health care. J Altern Complement Med. 2010;16(9):945-50.

12. Hollenberg D, Muzzin L. Epistemological challenges to integrative medicine: An anti-colonial perspective on the combination of complementary/alternative medicine with biomedicine. Health Sociol Rev. 2010;19(1):34-56.

13. Keshet Y, Ben-Arye E, Schiff E. Can holism be practiced in a biomedical setting? A qualitative study of the integration of complementary medicine to a surgical department. Health (London). 2012;16(6):585-601.

14. Kopansky-Giles D, Vernon H, Boon H, Steiman I, Kelly M, Kachan N. Inclusion of a CAM therapy (chiropractic care) for the management of musculoskeletal pain in an integrative, inner city, hospitalbased primary care setting. Altern. Med. Res. 2010;2(1):61-74.

15. Mansky PJ, Wallerstedt DB. Complementary medicine in palliative care and cancer symptom management. Cancer J. 2006;12(5):425-31.

16. Shorofi SA. Complementary and alternative medicine (CAM) among hospitalised patients: reported use of CAM and reasons for use, CAM preferred during hospitalisation, and the socio-demographic determinants of CAM users. Complement Ther Clin Pract. 2011;17(4):199-205.

17. Team V, Canaway R, Manderson L. Integration of complementary and alternative medicine information and advice in chronic disease management guidelines. Aust J Prim Health. 2011;17(2):142-9. 
18. Thorpe RD. Integrating biomedical and CAM approaches: the experiences of people living with HIV/AIDS. Health Sociol Rev. 2008;17(4):410-18.

19. Tippens KM, Oberg E, Bradley R. A dialogue between naturopathy and critical medical anthropology: toward a broadened conception of holistic health. Med Anthropol Q. 2012;26(2):257-70.

20. Templeman K, Robinson A. Integrative medicine models in contemporary primary health care. Complement Ther Med. 2011;19(2):84-92.

21. Ministry of Health. Policy guidelines on Traditional Medicine Development. MoH, Accra, Ghana. 2005. http://www.moh.gov.gh/wp-content/uploads/2016/02/TRADITIONAL-MEDICINE-POLICY.pdf.

22. Asare B. E. Developments made in herbal medicine practice in Ghana. . Modern Ghana, Accra, Ghana. [Accessed 2018-07-23]. https://www.modernghana.com/news/594410/developments-made-in-herbalmedicine-practice-in-ghana.html.

23. Barimah K. Traditional healers in Ghana: So near to the people, yet so far away from basic health care system. TANG [HUMANITAS MEDICINE]. 2016;6:9.1-9.6.

24. Browne G, Roberts J, Gafni A, Byrne C, Kertyzia J, Loney P. Conceptualizing and validating the human services integration measure. Int J Integr Care. 2004;4:e03-e03.

25. Bahadur A, Naqvi HS, Sarwar Z. Role of Monitoring and Supervision to Improve Health Service Delivery in Basic Health Units of Punjab, Pakistan. Information and Knowledge Management. 2016;6:66-72.

26. Kompaso S, Sridevi M. Employee Engagement: The Key to Improving Performance. International Journal of Business and Management. 2010;5.

27. Bjertnaes OA, Sjetne IS, Iversen HH. Overall patient satisfaction with hospitals: effects of patientreported experiences and fulfilment of expectations. BMJ Qual Saf. 2012;21(1):39-46.

28. Strandberg-Larsen M, Krasnik A. Measurement of integrated healthcare delivery: a systematic review of methods and future research directions. Int J Integr Care. 2009;9:e01-e01. doi:10.5334/ijic.305

29. Ahgren B, Axelsson R. Evaluating integrated health care: a model for measurement. Int J Integr Care. 2005;5:e01-e09.

30. Burns LR, Walston SL, Alexander JA, Zuckerman HS, Andersen RM, Torrens PR, et al. Just how integrated are integrated delivery systems? Results from a national survey. Health Care Manage Rev. 2001;26(1):20-39.

31. Devers KJ, Shortell SM, Gillies RR, Anderson DA, Mitchell JB, Erickson KL. Implementing organized delivery systems: an integration scorecard. Health Care Manage Rev. 1994;19(3):7-20.

32. Mensah EO, Aikins MK, Gyapong M, Anto F, Bockarie MJ, Gyapong JO. Extent of Integration of Priority Interventions into General Health Systems: A Case Study of Neglected Tropical Diseases Programme in the Western Region of Ghana. PLOS Neglected Tropical Diseases. 2016;10(5):e0004725.

33. World Health Organisation. Integrated Health Services - What and Why? WHO, Geneva, Switzerland. 2008. https://www.who.int/healthsystems/technical_brief_final.pdf.

\section{Tables}


Table 1

Integration principles and their respective elements of integration.

Integration principles

Comprehensive services

Elements of integration function

Scope of services covered

Coordinated services

Cooperation between services

Population health focus

Nature of referral system

Procurement

Supply chain system

Patient focus

Population-based needs assessment

Patient satisfaction

3Rs (i.e., rights, risks, respect) of service

Patient engagement \& participation

Treatment coverage

Geographic coverage

Standardized health care

Right of patients to use other services

Interpersonal teams

Clearly defined roles \& responsibilities

Shared protocols

Competing ideologies \& value

Mutual trust

Conflicting views about client interest

Diverse communication channels

Team meetings

Use of electronic information systems

Performance management

Monitoring \& supervision system

Performance appraisal system

Quality improvement system

Data collection \& analysis

Information systems

Computerized information systems

Communication capacity \& information flow

E-Health records linked to patients, payer and

administration

Seamless communication between care providers

System-wide patient registration \& scheduling

coordination

Integrated clinical \& financial information

Leadership interest in Information Technology

Congruence in organization culture

Organizational culture \&

leadership

Health workforce integration

Nature of working relationship among staff

Shared decision-making responsibilities

In-service training

Defined job description

Staff recruitment \& promotion procedure

Governance structure

Organogram

Accountability \& decision-making

Reporting

Diversified \& representative governance structure

Financial management

Auditing

Staff remuneration

Pooling of funds

Funding sources

Table 2

Interpretation of depth of integration scores 


\begin{tabular}{|c|c|c|}
\hline $\begin{array}{l}\text { Depth of } \\
\text { integration }\end{array}$ & Score & Interpretation \\
\hline Non-awareness & 0 & $\begin{array}{l}\text { Existing CAM services not aware of other programmes or services or } \\
\text { the existing CAM services are segregated from other services in the } \\
\text { facility }\end{array}$ \\
\hline Awareness & 1 & $\begin{array}{l}\text { CAM services are linked to other programmes or services in the } \\
\text { hospital but they organize their activities solely on the basis of their } \\
\text { own program or service mission. }\end{array}$ \\
\hline Communication & 2 & $\begin{array}{l}\text { CAM services actively share information and communication on a } \\
\text { formal basis }\end{array}$ \\
\hline Cooperation & 3 & $\begin{array}{l}\text { CAM programmes and services modify their own service planning to } \\
\text { avoid service duplication or to improve links among services. }\end{array}$ \\
\hline Collaboration & 4 & $\begin{array}{l}\text { CAM services jointly plan their services offered and modify their own } \\
\text { services as a result of mutual consultations and advice. }\end{array}$ \\
\hline
\end{tabular}

Source: Browne et al (2004)

Table 3

Score ranges and indicator classification

\begin{tabular}{c|l}
\hline Score range & Indicator classification \\
\hline $0.0-0.49$ & Very little integration \\
\hline $0.5-0.99$ & Little integration \\
\hline $1.0-1.49$ & Mild integration \\
\hline $1.5-1.99$ & Moderate integration \\
\hline $2.0-2.49$ & Good integration \\
\hline $2.5-2.99$ & Very good integration \\
\hline $3.0-3.49$ & Excellent integration \\
\hline $3.5-4.00$ & Perfect integration \\
\hline
\end{tabular}

Table 4

Background characteristics of participants

\begin{tabular}{l|l}
\hline Items & Number (\%) \\
\hline Sex & $5(55.6)$ \\
Male & $4(44.4)$ \\
\hline Age & \\
$<45$ & $4(44.4)$ \\
$>45$ & $3(33.4)$ \\
Not stated & $2(22.2)$ \\
\hline Duration spent in position & $5(55.6)$ \\
$<5$ years & $4(44.4)$ \\
$>5$ years & \\
\hline Total & $9(100.0)$ \\
\hline
\end{tabular}

Table 5

Drivers of CAM integration 


\begin{tabular}{|c|c|c|c|c|}
\hline Integration principles & $\begin{array}{l}\text { Elements of integration } \\
\text { function }\end{array}$ & $\begin{array}{l}\text { Perceived depth of } \\
\text { integration }\end{array}$ & \multicolumn{2}{|c|}{$\begin{array}{l}\text { Service indicator } \\
\text { classification }\end{array}$} \\
\hline Patient focus & Patient satisfaction & 2.56 & $\begin{array}{l}\text { Very } \\
\text { Integration }\end{array}$ & Good \\
\hline Treatment coverage & $\begin{array}{l}\text { Right of patients to use } \\
\text { other services }\end{array}$ & 3.11 & $\begin{array}{l}\text { Excellent } \\
\text { Integration }\end{array}$ & \\
\hline $\begin{array}{l}\text { Standardized health } \\
\text { care }\end{array}$ & Interpersonal teams & 2.56 & $\begin{array}{l}\text { Very } \\
\text { Integration }\end{array}$ & Good \\
\hline $\begin{array}{l}\text { Performance } \\
\text { management }\end{array}$ & $\begin{array}{ll}\text { Monitoring } & \text { and } \\
\text { supervision system }\end{array}$ & 2.78 & $\begin{array}{l}\text { Very } \\
\text { Integration }\end{array}$ & Good \\
\hline $\begin{array}{l}\text { Organizational culture } \\
\text { and leadership }\end{array}$ & $\begin{array}{l}\text { Nature of working } \\
\text { relationship among staff }\end{array}$ & 2.67 & $\begin{array}{l}\text { Very } \\
\text { Integration }\end{array}$ & Good \\
\hline Governance structure & Reporting & 2.89 & $\begin{array}{l}\text { Very } \\
\text { Integration }\end{array}$ & Good \\
\hline \multirow[t]{3}{*}{ Financial management } & Auditing & 2.78 & $\begin{array}{l}\text { Very } \\
\text { Integration }\end{array}$ & Good \\
\hline & Staff remuneration & 2.67 & $\begin{array}{l}\text { Very } \\
\text { Integration }\end{array}$ & Good \\
\hline & Funding sources & 3.11 & $\begin{array}{l}\text { Excellent } \\
\text { Integration }\end{array}$ & \\
\hline
\end{tabular}

\section{Figures}

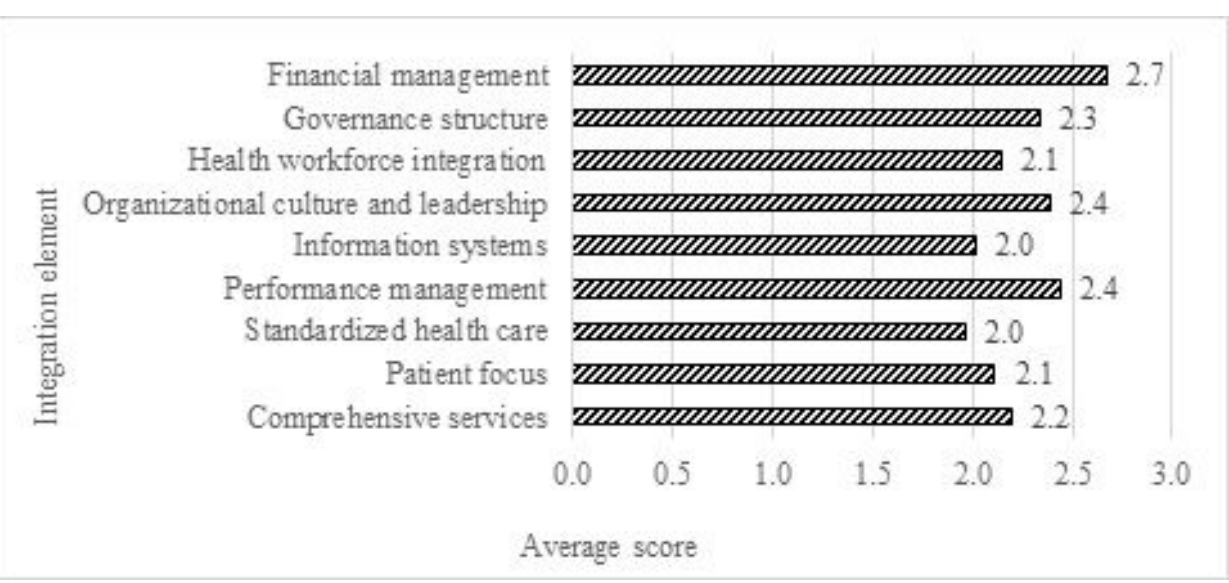

Figure 1

Self-reported depth of integration. 


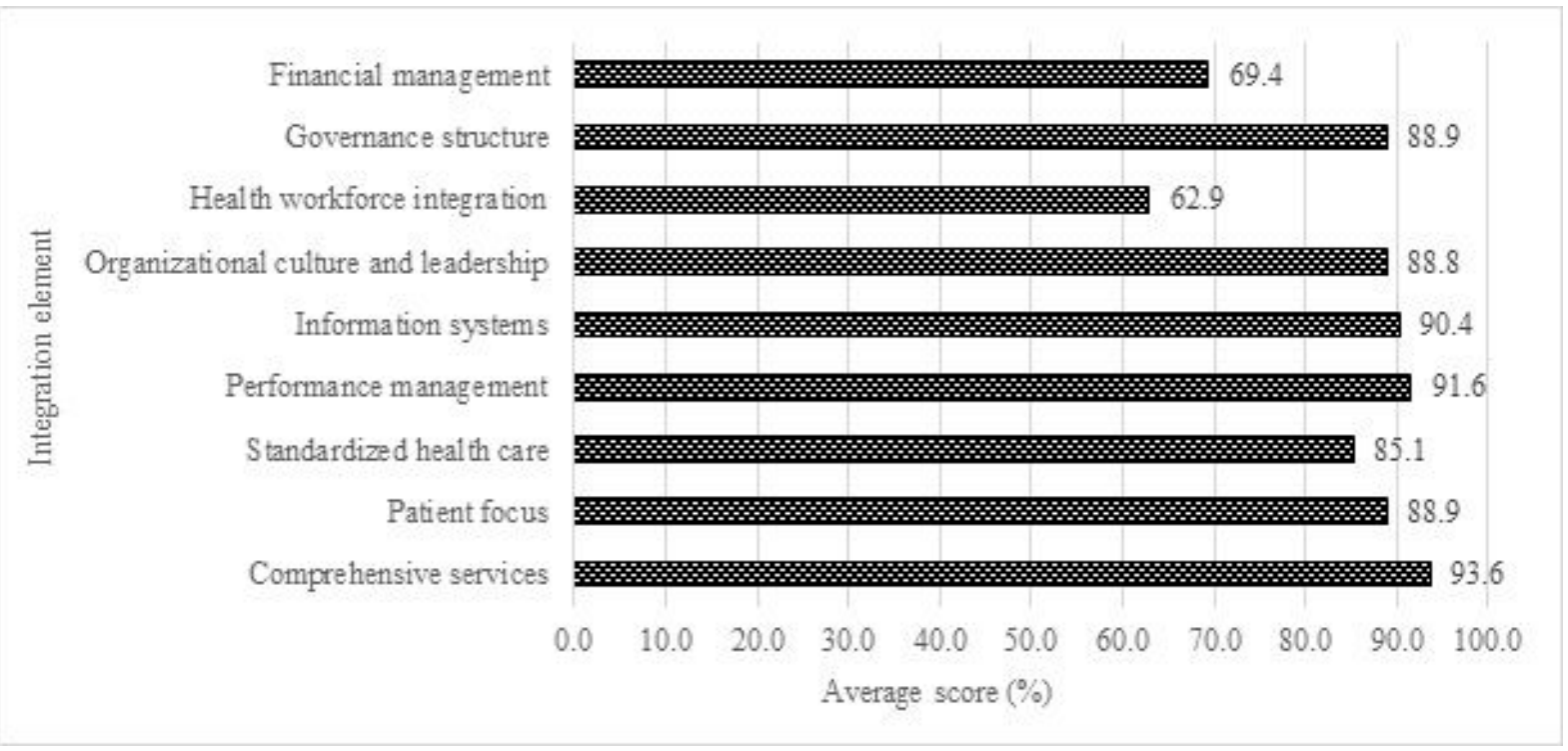

\section{Figure 2}

Perceived scope of integration elements.

\section{Supplementary Files}

This is a list of supplementary files associated with this preprint. Click to download.

- CONSORTextensionforPilotandFeasibilityTrialsChecklist.doc 